\title{
Reverse Strategy for the Management of Rectal Cancer: A New Therapeutic Approach
}

\author{
Emmanouil P Pappou* \\ Department of Colorectal Surgery, Memorial Sloan Kettering Cancer Center, USA
}

Submission: November 20, 2017; Published: December 14, 2017

*Corresponding author: Emmanouil P Pappou, Colorectal Service, Department of Surgery, Memorial Sloan Kettering Cancer Center, 1275 York Avenue, New York, USA 10065, Email: manolis.pappou@gmail.com

\section{Clinical Scenario}

An otherwise healthy 45-year old woman presents to clinic for evaluation of new-onset rectal bleeding. Digital rectal examination revealed a $5 \mathrm{~cm}$ mobile mass, approximately 8 $\mathrm{cm}$ above the anal verge. Colonoscopy with biopsy confirmed the presence of a moderately-differentiated adenocarcinoma. Preoperative CEA was $220 \mathrm{ng} / \mathrm{mL}$. Pelvic MRI revealed two enlarged perirectal nodes in addition to the $5 \mathrm{~cm}$ rectal mass (clinically stage T3N1). Staging CT demonstrated the presence of 4 liver lesions in segments III, IVB, VI, and VIII, consistent with liver metastases, all less than $4 \mathrm{~cm}$ in size.

What sequence of events would you best choose for this patient?

a) Chemo radiotherapy followed by resection of rectal cancer, followed by chemotherapy and resection of liver metastases.

b) Chemo radiotherapy followed by resection of rectal cancer, followed by resection of liver metastases and adjuvant chemotherapy.

c) Chemo radiotherapy, followed by simultaneous resection of rectal cancer and liver metastases, followed by adjuvant chemotherapy.

d) Resection of liver metastases, followed by radio chemotherapy and resection of rectal cancer.

e) Neoadjuvant chemotherapy, followed by liver surgery, followed by chemo radiotherapy with subsequent resection of rectal cancer.

\section{Introduction}

Rectal cancer is a common malignancy. The American Cancer Society estimates that this year in the United States rectal cancer will affect more than 40,000 new patients [1]. The management of rectal cancer has rapidly changed during the last decade. Advances in surgical techniques and improvement in radio and chemotherapy have enhanced both local control and cure rates, allowing a substantial increase of survival of patients. However, survival of patients with metastatic disease is often limited. The liver is the most frequent site of metastatic disease in rectal cancer. In fact, nearly 15-25\% of patients with rectal cancer present with synchronous liver metastases [2]. In this population, the liver metastases are the main determinants for prognosis of the patient. Specifically the synchronous presentation of liver metastases has been associated with poor outcomes [3-5]. However, the increase of new multimodality options to treat this group of patients is continuing and major advances have been made.

\section{Options}

The optimal sequencing of systemic and local therapy in rectal cancer with synchronous liver metastases is not standardized. In fact, all options in the clinical vignette above are used in the treatment of the disease. The traditional treatment of synchronous rectal liver metastases has been resection of the primary tumor with or without neoadjuvant pelvic radiation and radio sensitizing chemotherapy-depending on the presence of locally advanced disease-followed by long periods of chemotherapy and finally, if there is no disease progression, liver resection (option $A$ in the clinical vignette) $[6,7]$.

Following this treatment schedule, it may take up to 3-6 months before definite metastatic therapy is administered [8]. Complications of the primary tumor operation, such as persistent wound infections, an astomotic leak, or low-pelvic abscesses are not uncommon in rectal surgery and can delay treatment for the liver metastases, allowing progression of the disease. Moreover, only few patients can benefit from this strategy, either because the metastases are considered unresectable from the beginning, or because they progress during treatment of the primary tumor. Since the primary determinant of long-term survival is control of the metastatic disease, many clinicians have argued that starting with chemotherapy first to treat the systemic disease is the best treatment plan. 


\section{The Reverse Strategy}

In 2006, Mentha and colleagues first published their experience with a "reverse strategy" for the treatment of advanced colorectal cancers with synchronous liver metastases [9]. In this strategy, a highly effective neoadjuvant chemotherapy directed against the liver metastases is given first, followed by resection of the colorectal liver metastases, and the primary colorectal tumor resection is performed as a last step at a separate operation after preoperative chemo radiation when necessary (option $\mathrm{E}$ in the clinical vignette).

The rationale of this strategy lies on the assumption that when synchronous liver metastases are present in rectal cancer, patients have a systemic disease, and that treatment should be systemic from the start without delay, instead of focusing attention to the primary tumor as is done with the traditional approach. This strategy is supported by the fact that tumorrelated complications (e.g. bleeding, perforation, obstruction) are rare in patients with stage IV colorectal cancer who receive up-front chemotherapy $[10,11]$.

\section{Advantages of the Reverse Strategy}

Theoretical advantages of the reverse strategy are following:

A. It allows prompt initiation of neoadjuvant chemotherapy directed against the metastatic disease, which treats and limits the liver tumor burden, a step necessary for long-term cure.

B. It downstages and thereby increases the respectability of liver disease in patients initially not deemed suitable for surgery, which may lead to a longer survival in patients who respond to chemotherapy [12].

C. Response to neoadjuvant chemotherapy serves as a biologic marker of chemo sensitivity and identifies patients with a favorable prognosis, a feature which could spare ineffective surgical treatment in patients with aggressive biology [13-15].

D. After treatment of the metastatic disease with neoadjuvant chemotherapy and liver surgery, radiotherapy directed against the primary rectal cancer can be delivered in an unhurried fashion, once the metastatic disease in the liver is under control.

\section{Studies on the Reverse Strategy}

Data regarding the oncologic outcomes using the reverse strategy are limited. In the first prospective study of 20 patients with advanced synchronous colorectal liver metastases and a primary colorectal tumor in place, Mentha and colleagues demonstrated the feasibility and safety of this approach, with an overall 4 year survival rate of $56 \%$ and a median survival of 46 months (3.8 years) [9]. 11 of these 20 reported patients had rectal cancer, in the remainder the primary cancer was in the colon. The definition of advanced metastatic disease in the study was based on the clinical risk score described by Fong et al. [16].

It is important to note that patients in this study had a fairly significant liver tumor burden; the median number of liver metastases was 5, $70 \%$ had more than four liver metastases, 60 $\%$ had liver metastases larger than $5 \mathrm{~cm}$, and $70 \%$ had bilobar liver disease. Sixteen of the 20 patients enrolled in the study were able to undergo $\mathrm{R} 0$ resection of the liver metastases and the primary colorectal tumors, resulting in a respectability rate of $80 \%$. This high respectability rate despite the fairly advanced nature of the disease is attributed to the efficacy of modern neoadjuvant chemotherapy, early surgical intervention after initial systemic control (in most patients 2-3 weeks after the third course of chemotherapy) and the fairly frequent use of portal vein embolization, or two-stage hepatectomy, techniques which ensure adequate liver function after liver resection.

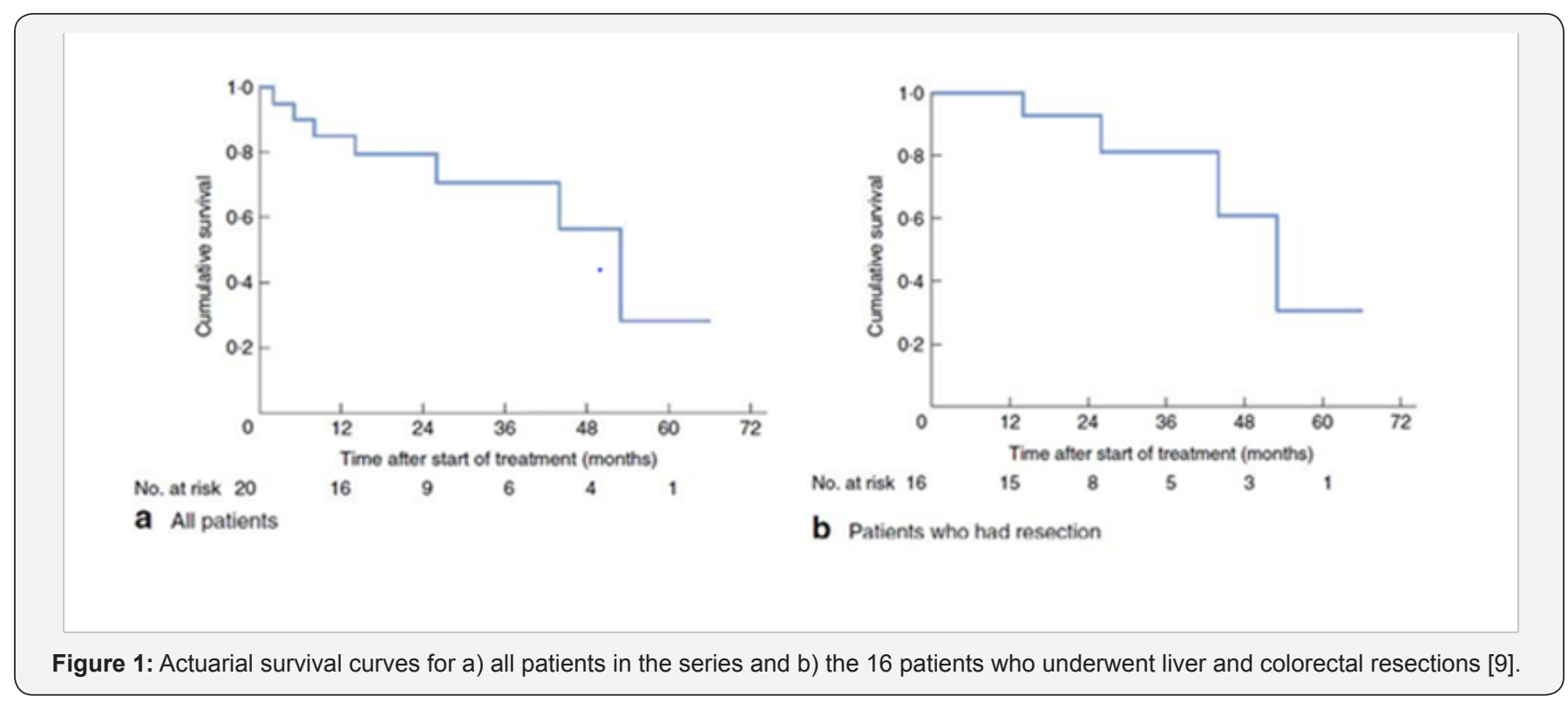


Survival rates for all 20 patients of the study and for the 16 patients who underwent surgery in this pilot investigation were higher than rates published in the literature for disease of similar severity $[16,17]$. Survival rates for all 20 patients in the study were $79 \%$ at 2 years, and $71 \%$ at 3 years, whereas for the 16 patients who underwent surgery survival was $93 \%$ at 2 years and $83 \%$ at 3 years (Figure 1).

An update of this series was published by Mentha et al. [18]. The updated report included 15 more patients to reach a total of 35. All of them had non-obstructive tumors. Overall, thirteen of the 35 patients ( $37 \%$ ) had a rectal primary. Only 1 added patient could not complete the program, raising the total number of patients who could not complete the program to 5 out of 35 (14\%). In the 30 patients (86\%) who were able to complete all phases of the program (neoadjuvant chemotherapy, liver surgical clearance, pelvic radiotherapy if indicated and removal of the primary tumor in that order), there was no preoperative mortality.

Complications of liver surgery were noted in 5 of the 30 patients (17\%). Nine patients (30\%) had a 2-step hepatectomy with a portal vein embolization, or right portal vein ligation. Interestingly, simultaneous liver and primary tumor surgery was performed in 7 of the 30 patients ( $23 \%$ ) if the liver resection was minor and considered without any risk of postoperative failure, however only 1 of them (3\%) had rectal cancer, in the rest the primary tumor was in the colon. Considering complications of the colorectal surgery, only 1 of the 30 (3\%) patients had an astomotic leak requiring conversion to a Hartmann's procedure.

It is important to note that half of the patients included in this study had liver metastases that were technically unresectable before chemotherapy according to criteria defined in a consensus survey [19]. In previous reports, respectability rates of $12-54 \%$ (R0 and R1 resection combined) have been reported with systemic chemotherapy, whereas in this study R0 resection was achieved in $86 \%$ of patients $[15,20]$. This is particularly relevant, as the expected overall survival of patients with unresectable liver metastases remains significantly inferior to those in whom curative hepatic resection is achieved $[6,21]$.

Despite the high respectability rate in this study, overall recurrences were observed in 20 of the 30 patients (66\%). At the end of follow-up only 10 of the 30 patients were alive with no evidence of disease. This demonstrates that despite the prolongation of survival in patients with severe disease who would have received only palliative treatments in the past, still definite cure with the use of reverse strategy was achieved in a minority of them. Considering the 35 patients who participated in the study as intention to treat, the overall actuarial survival rate at 5 years was $30 \%$, with a median survival of 44 months, and for the 30 patients who completed the entire program $31 \%$ and 44 months respectively (Figure 2).

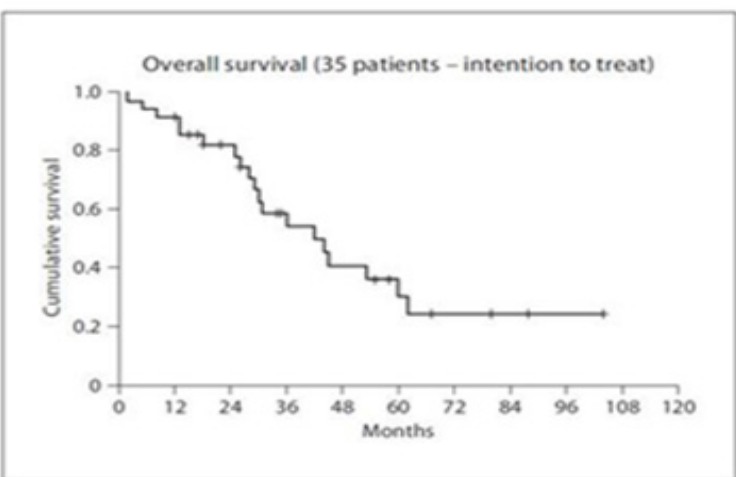

a. Overall survival of all patients with the reverse strategy.

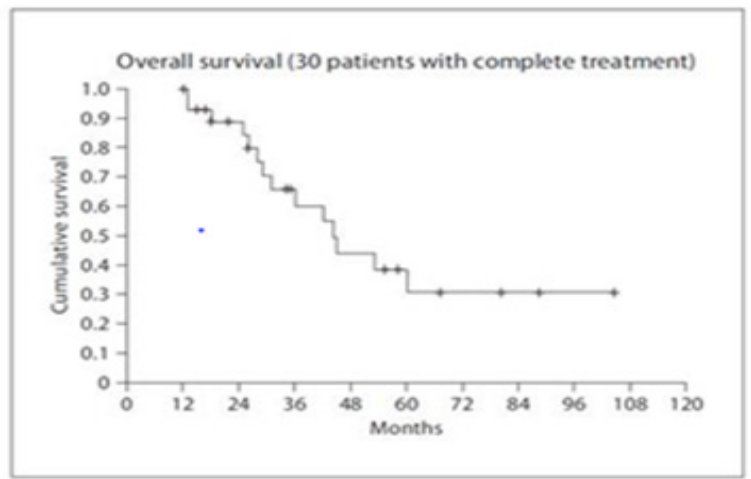

b. Overall survival of the 30 patients who completed the full treatment.

Figure 2: Overall survival for a) all patients with the reverse strategy as intention to treat and b) for the 30 patients who completed the full treatment [18].

In another report from the Netherlands, Verhoef and colleagues confirmed the feasibility of the reverse strategy in locally advanced rectal cancer (clinically $>\mathrm{T} 3$, or tumor $>5 \mathrm{~cm}$, or $\mathrm{N}+$ ) and synchronous liver metastases [22]. This was the first report to include only patients with rectal cancer, as opposed to the reports by Mentha and colleagues which contained colon cancer patients as well. Of the 23 patients in this study, 9 (40\%) had more than 3 metastases, 12 (52\%) had bilobar liver disease, and in the majority of patients ( $86 \%$ ) the metastases were less than $5 \mathrm{~cm}$.

It is important to note that in 6 of the 23 patients (26\%) the presenting symptom was obstruction, 4 of which were operated on for diversion ileostomy or colostomy, and that in general, symptoms of presentation such as bleeding, pain, or diarrhea rapidly disappeared rapidly after the first or second 
cycle of chemotherapy, yet 1 patient ( $4 \%$ ) had blowout of the cecum during his third cycle of chemotherapy and required emergency laparotomy with diversion colostomy. Additionally, one patient refused the reverse strategy after initial consent and underwent a low-anterior resection in combination with a right hepatectomy. Sixteen patients (73\%) in this study completed the full treatment protocol.

Considering surgery, 20 patients (91\%) underwent successfully R0 liver resection, with $10 \%$ morbidity, and 16 patients $(73 \%)$ underwent rectal surgery (63\% low-anterior resection, $37 \%$ abdominoperineal resection) after chemo radiation without any major complications. Median follow-up was 18 months ( $1 \frac{1}{2}$ years) for all 23 patients in this study and all 16 patients $(73 \%)$ who completed the full treatment protocol were alive at that time, but 4 (25\%) developed recurrence of metastases, 2 of which had irresectable disease.

Finally, in a retrospective study from M.D. Anderson published in 2010, Brouquet and colleagues analyzed records of 156 patients with synchronous colorectal liver metastases and intact colorectal primary tumor, who received 3 different surgical strategies, either a classic surgical strategy (primary tumor resection before liver), or a combined (synchronous resection of primary and liver), or reverse strategy (liver before primary after preoperative chemotherapy) [23]. In the majority of patients who underwent the classic strategy, chemotherapy was administered between resection of the primary and the liver metastases, whereas in patients who underwent the simultaneous or reverse strategy chemotherapy was administered before operation.

This was the first study to compare head-to-head morbidity, mortality and overall survival rates of 3 different modalities used in the treatment of colorectal cancer with synchronous liver metastases, showing that the reverse approach is particularly useful in patients with advanced disease, leading to an increase in respectability in patients with advanced colorectal metastases, with oncologic results similar to the classical and the combined approach [24,25].

In this study, 27 of the 41 patients (65\%) were able to complete the full treatment protocol of the reverse strategy. Among those who completed treatment, in 19 (70\%) the primary was in the rectum, and in $8(30 \%)$ in the colon. Of the 14 patients who did not have resection of the primary tumor, 9 (64\%) had a rectal primary. The most common cause for no resection was disease progression in 9 (64\%), followed by complete response of primary in 2 patients, postoperative death after liver resection in 1 patient, progression of primary tumor in 1 patient, and loss of follow up in 1 patient. Symptoms related to the primary tumor and requiring colostomy occurred in 2 patients considered for a reverse strategy ( 2 of $41,5 \%$ ). Seven of the 14 patients who did not have resection were dead at last follow-up, most common cause of death being metastatic disease progression in 5 of them (82\%).
Major liver resection was performed in 24 patients (89\%) in the reverse strategy group and 63 patients (55\%) in the two other groups, and this finding was statistically significant (p $<0.001$ ). This finding is interesting, given the fact that the median maximum tumor diameter of liver metastases respected in the reverse strategy group was larger than the other two treatment groups, finding that was statistically significant as well. This indicates that patients in the reverse strategy had a larger liver tumor burden to begin with and despite this, they were able to undergo successful liver surgery more often than in the other groups. Despite more extensive disease in patients undergoing the reverse strategy, its use led to the expansion of respectability of liver metastases.

Three and 5 year overall survival rates, respectively, were 58 $\%$ and $48 \%$ in the classic group, $65 \%$ and $55 \%$ in the combined group, and $79 \%$ and $39 \%$ in the reverse group. Overall the rate of recurrence was $63 \%$ and there was no statistical difference among the groups. Cumulative postoperative morbidity and mortality rates were not statistically different between the three different groups. The conclusion of the study was that classic, combined, and reverse strategies were associated with similar outcomes, despite more extensive disease in patients in the reverse strategy group and that the reverse strategy is a safe alternative for treatment of advanced colorectal liver metastases in patients with an asymptomatic primary colorectal tumor.

\section{Potential Disadvantages of the Reverse Strategy}

The use of the reverse strategy for the treatment of advanced rectal tumors with synchronous colorectal liver metastases may carry several potential pitfalls that need to be taken into consideration. A potential disadvantage of the reverse strategy is progression of initially respectable disease during chemotherapy, so that metastases become unresectable. In the era of highly effective chemotherapy with response rates close to $70-80 \%$ this has become more a theoretical concern. In fact, in the studies by Mentha and colleagues this phenomenon was not encountered.

Only 3 patients treated with the reverse strategy progressed during chemotherapy, none of whom was respectable upfront. In the study by Brouquet and colleagues progression while on chemotherapy was seen in 9 patients, whereas in the study by Verhoef et al. $68 \%$ of patients undergoing the reverse strategy had partial response to chemotherapy, $27 \%$ had stable disease and $1(5 \%)$ had complete remission after completion of chemotherapy. Still, progression of the disease while on chemotherapy does not preclude surgery if the disease is still respectable. Moreover, progression to irresectable disease after a few cycles of chemotherapy suggests that this subgroup of patients have very aggressive disease and can hardly be helped by surgery $[15,26]$.

A more concrete pitfall of the reverse strategy is progression of the disease after initial response. Response to chemotherapy may not last long, there is a possibility that that disease may 
progress after initial response, and thus surgery should be performed as soon as respectability is technically possible, a concern raised by Mentha and colleagues. In fact, in all 3 reported studies on the reverse strategy, radiographic assessment of tumor response during chemotherapy was made every two or three cycles and surgery was scheduled once the patient was considered respectable.

Another concern of the reverse strategy is the problem of vanishing metastases. Disappearance of smaller liver lesions after several lines of chemotherapy is being increasingly described, making their identification intraoperatively difficult. Emerging data suggest that the risk of regrowth of these lesions is high, and it is recommended that they be identified and respected either based on anatomic landmarks, or with the use of intraoperative ultrasonography [27-30].

Another consideration of the reverse strategy is the chemotherapy-related parenchymal liver damage that may occur during preoperative chemotherapy, rendering liver surgery more difficult and potentially hazardous [31]. This limitation can be overcome by use of modern therapeutic approaches to liver metastases such as portal vein embolization and two-stage hepatectomy, which may provide adequate liver function after liver resection [32-35]. Moreover, the short chemotherapy course provided during the reverse therapy (2-4 cycles before liver resection) may limit this event, since it is already known from the literature that short courses of neoadjuvant chemotherapy do not increase morbidity or mortality after hepatectomy [36,37].

\section{Conclusion}

Long-term survival of patients with hepatic colorectal metastases is improving over time, thanks to advancement of surgical techniques, effective chemotherapy and multimodality management of the disease [6]. The optimal management of patients with locally advanced rectal cancer and synchronous liver metastases is still not well defined, because treatment of both the primary and the metastatic deposits has to be planned.

The reverse strategy has been demonstrated to be a safe and successful alternative that may used as the preferred treatment in patients with locally advanced rectal cancer and synchronous liver metastases. This strategy allows immediate treatment of the prognostically important site (liver metastases), it may effectively down size the metastatic disease, increasing the chances of respectability in patients initially not deemed suitable for surgery and may identify patients with incurable metastatic disease and avoid needless radical surgery. Despite the increase in respectability with the reverse strategy, the high rate of recurrence $(60-70 \%)$ remains an area for further research and improvement.

So far, all three approaches, the classic, the combined and the reverse have shown similar outcomes in terms of survival, morbidity and mortality. A main limitation of rectal surgery combined with major liver resection during the same session (combined approach) is the major morbidity and mortality of this strategy, especially after heavy chemotherapy [38,39]. This strategy can be offered to only $18-56 \%$ of patients [40-42]. The reverse strategy allows safe and successful resection of both primary and liver metastases in a sequential fashion, with acceptable morbidity and mortality, expanding the therapeutic armamentarium available. All existing therapeutic approaches (classic, combined, reverse), should not be seen as competitive, but rather as complimentary; a multidisciplinary approach including medical and radiation oncologists, radiologists and hepatobiliary surgeons may define the most optimal strategy for each patient individually suffering from advanced rectal cancer with synchronous liver metastases and offer the best chance for cure. Further randomized trials in the future will determine the ideal algorithm for the management of these patients.

\section{References}

1. American Cancer Society (2011) Colorectal Cancer Facts \& Figures 2011-2013. Atlanta: American Cancer Society.

2. Manfredi S, Lepage C, Hatem C, Coatmeur O, Faivre J, et al. (2006) Epidemiology and management of liver metastases from colorectal cancer. Ann Surg 244(2): 254-259.

3. Nordlinger B, Guiguet M, Vaillant JC, Balladur P, Boudjema K, et al. (1996) Surgical resection of colorectal carcinoma metastases to the liver. A prognostic scoring system to improve case selection, based on 1568 patients. Association Francaise de Chirurgie. Cancer 77(7): 1254-1262.

4. Simmonds PC, Primrose JN, Colquitt JL, Garden OJ, Poston GJ, et al, (2006) Surgical resection of hepatic metastases from colorectal cancer: a systematic review of published studies. Br J Cancer 94(7): 982-999.

5. Viganò L, Ferrero A, Lo Tesoriere R, Capussotti L (2008) Liver surgery for colorectal metastases: results after 10 years of follow-up. Longterm survivors, late recurrences, and prognostic role of morbidity. Ann Surg Oncol 15(9): 2458-2464.

6. Choti MA, Sitzmann JV, Tiburi MF, Sumetchotimetha W, Rangsin R, et al. (2002) Trends in long-term survival following liver resection for hepatic colorectal metastases. Ann Surg 235(6): 759-766.

7. Wicherts DA, Miller R, de Haas RJ, Bitsakou G, Vibert E, et al. (2008) Long-term results of two-stage hepatectomy for irresectable colorectal cancer liver metastases. Ann Surg 248(6): 994-1005.

8. Bosset JF, Collette L, Calais G, Mineur L, Maingon P, et al. (2006) Chemotherapy with preoperative radiotherapy in rectal cancer. $\mathrm{N}$ Engl J Med 355(11): 1114-1123.

9. Mentha G, Majno PE, Andres A, Rubbia-Brandt L, Morel P, et al. (2006) Neoadjuvant chemotherapy and resection of advanced synchronous liver metastases before treatment of the colorectal primary. Br J Surg 93(7): 872-878.

10. Poultsides GA, Servais EL, Saltz LB, Patil S, Kemeny NE, et al. ( 2009) Outcome of primary tumor in patients with synchronous stage IV colorectal cancer receiving combination chemotherapy without surgery as initial treatment. J Clin Oncol 27(20): 3379-3384.

11. Benoist S, Pautrat K, Mitry E, Rougier P, Penna C, etal. (2005) Treatment strategy for patients with colorectal cancer and synchronous irresectable liver metastases. Br J Surg 92(9): 1155-1160.

12. Alberts SR, Horvath WL, Sternfeld WC, Goldberg RM, Mahoney MR, et al. (2005) Oxaliplatin, fluorouracil, and leucovorin for patients with unresectable liver-only metastases from colorectal cancer: a North Central Cancer Treatment Group phase II study. J Clin Oncol 23(36): 9243-9249. 
13. Adam R, Wicherts DA, de Haas RJ, Aloia T, Lévi F, et al. (2008) complete pathologic response after preoperative chemotherapy for colorectal liver metastases: myth or reality? J Clin Oncol 26(10): 1635-1641.

14. Rubbia-Brandt L, Giostra E, Brezault C, Roth AD, Andres A, et al. (2007) Importance of histological tumor response assessment in predicting the outcome in patients with colorectal liver metastases treated with neo-adjuvant chemotherapy followed by liver surgery. Ann Oncol 18(2): 299-304

15. Adam R, Pascal G, Castaing D, Azoulay D, Delvart V, et al. (2004) Tumor progression while on chemotherapy: a contraindication to liver resection for multiple colorectal metastases? Ann Surg 240(6): 1052 1061; discussion 1061-1064.

16. Fong Y, Fortner J, Sun RL, Brennan MF, Blumgart LH, et al. (1999) Clinical score for predicting recurrence after hepatic resection for metastatic colorectal cancer: analysis of 1001 consecutive cases. Ann Surg 230(3): 309-318; discussion 318-321.

17. Mala T, Bøhler G, Mathisen Ø, Bergan A, Søreide O, et al. (2002) Hepatic resection for colorectal metastases: can preoperative scoring predict patient outcome? World J Surg 26(11): 1348-1353.

18. Mentha G, Roth AD, Terraz S, Giostra E, Gervaz P, et al. (2008) Liver first approach in the treatment of colorectal cancer with synchronous liver metastases. Dig Surg 25(6): 430-435

19. Poston GJ (2004) surgical strategies for colorectal liver metastases. Surg Oncol 13(2-3): 125-136.

20. Folprecht G, Grothey A, Alberts S, Raab HR, Köhne CH (2005) Neoadjuvant treatment of unresectable colorectal liver metastases: correlation between tumour response and resection rates. Ann Oncol 16(8): 1311-1319.

21. Abdalla EK, Vauthey JN, Ellis LM, Ellis V, Pollock R, et al. (2004) Recurrence and outcomes following hepatic resection, radiofrequency ablation, and combined resection/ablation for colorectal liver metastases. Ann Surg 239(6): 818-825; discussion 825-827.

22. Verhoef C, van der Pool AE, Nuyttens JJ, Planting AS, Eggermont AM, et al. (2009) The liver-first approach for patients with locally advanced rectal cancer and synchronous liver metastases. Dis Colon Rectum 52(1): 23-30.

23. Brouquet A, Mortenson MM, Vauthey JN, Rodriguez-Bigas MA, Overman MJ, et al. (2010) Surgical strategies for synchronous colorectal liver metastases in 156 consecutive patients: classic, combined or reverse strategy? J Am Coll Surg 210(6): 934-941.

24. Andreou A, Aloia TA, Brouquet A, Vauthey JN (2011) Recent advances in the curative treatment of colorectal liver metastases. Gastrointest Cancer Res 4(4 Suppl 1): S2-8.

25. Yang AD, Brouquet A, Vauthey JN (2010) Extending limits of resection for metastatic colorectal cancer: risk benefit ratio. J Surg Oncol 102(8): 996-1001.

26. Capussotti L, Muratore A (2006) Neoadjuvant chemotherapy and resection of advanced synchronous liver metastases before treatment of the colorectal primary (Br J Surg) 2006; 93: 872-878. Br J Surg 93(12): 1564; author reply 1564.

27. Benoist S, Brouquet A, Penna C, Julié C, El Hajjam M, et al. (2006)
Complete response of colorectal liver metastases after chemotherapy: does it mean cure? J Clin Oncol 24(24): 3939-3945.

28. Carpenter S, Fong Y (2010) Management of disappearing colorectal hepatic metastases. Adv Surg 44: 269-279.

29. van Vledder MG, de Jong MC, Pawlik TM, Schulick RD, Diaz LA, et al. (2010) Disappearing colorectal liver metastases after chemotherapy: should we be concerned? J Gastrointest Surg 14(11): 1691-1700.

30. Gaujoux S, Goéré D, Dumont F, Souadka A, Dromain C, et al. (2011) complete radiological response of colorectal liver metastases after chemotherapy: what can we expect? Dig Surg 28(2): 114-120.

31.Zorzi D, Laurent A, Pawlik TM, Lauwers GY, Vauthey JN, et al., Chemotherapy-associated hepatotoxicity and surgery for colorectal liver metastases. Br J Surg 94(3): 274-286.

32. Jaeck D, Oussoultzoglou E, Rosso E, Greget M, Weber JC, et al. (2004) A two-stage hepatectomy procedure combined with portal vein embolization to achieve curative resection for initially unresectable multiple and bilobar colorectal liver metastases. Ann Surg 240(6): 1037-1049; discussion 1049-1051.

33. Narita M, Oussoultzoglou E, Fuchshuber P, Pessaux P, Chenard MP, et al. (2012) What Is a Safe Future Liver Remnant Size in Patients Undergoing Major Hepatectomy for Colorectal Liver Metastases and Treated by Intensive Preoperative Chemotherapy? Ann Surg Oncol 19(8): 2526-2538.

34. Chun YS, Laurent A, Maru D, Vauthey JN, et al. (2009) Management of chemotherapy-associated hepatotoxicity in colorectal liver metastases. Lancet Oncol 10(3): 278-286.

35. Chun YS, Vauthey JN, Ribero D, Donadon M, Mullen JT, et al. (2007) Systemic chemotherapy and two-stage hepatectomy for extensive bilateral colorectal liver metastases: perioperative safety and survival. J Gastrointest Surg 11(11): 1498-1504; discussion 1504-1505.

36. Allen PJ, Kemeny N, Jarnagin W, DeMatteo R, Blumgart L, et al. (2003) Importance of response to neoadjuvant chemotherapy in patients undergoing resection of synchronous colorectal liver metastases. J Gastrointest Surg 7(1): p. 109-115; discussion 116-117.

37. Karoui M, Penna C, Amin-Hashem M, Mitry E, Benoist S, et al. (2006) Influence of preoperative chemotherapy on the risk of major hepatectomy for colorectal liver metastases. Ann Surg 243(1): 1-7.

38. Tanaka K, Shimada H, Matsuo K, Nagano Y, Endo I, et al. (2004) Outcome after simultaneous colorectal and hepatic resection for colorectal cancer with synchronous metastases. Surgery 136(3): 650-659.

39. Vogt P, Raab R, Ringe B, Pichlmayr R (1991) Resection of synchronous liver metastases from colorectal cancer. World J Surg 15(1): 62-67.

40. Lyass S, Zamir G, Matot I, Goitein D, Eid A, et al. (2001) Combined colon and hepatic resection for synchronous colorectal liver metastases. J Surg Oncol 78(1): 17-21.

41. Martin R, Paty P, Fong Y, Grace A, Cohen A, et al. (2003) Simultaneous liver and colorectal resections are safe for synchronous colorectal liver metastasis. J Am Coll Surg 197(2): 233-241; discussion 241-242.

42. Weber JC, Bachellier P, Oussoultzoglou E, Jaeck D, et al. Simultaneous resection of colorectal primary tumour and synchronous liver metastases. Br J Surg 90(8): 956-962. 


\section{Open Access Journal of Surgery}

This work is licensed under Creative Commons Attribution 4.0 Licens

DOI: 10.19080/OAJS.2017.07.555710
Your next submission with Juniper Publishers will reach you the below assets

- Quality Editorial service

- Swift Peer Review

- Reprints availability

- E-prints Service

- Manuscript Podcast for convenient understanding

- Global attainment for your research

- Manuscript accessibility in different formats

( Pdf, E-pub, Full Text, Audio)

- Unceasing customer service

Track the below URL for one-step submission https://juniperpublishers.com/online-submission.php 